\title{
On the Training of Professional Translators in UK Universities and Its Implications for Chinese Universities
}

\author{
Feng Wang \\ School of Foreign Studies \\ Yangtze University \\ Jingzhou, China \\ School of Foreign Languages and Cultures \\ Nanjing Normal University \\ Nanjing, China \\ CenTraS, University College London \\ London, UK
}

\begin{abstract}
After an introduction to the training of professional translator in UK universities including the University of Manchester, University College London and the University of Leeds, the implications to Chinese universities are discussed in terms of translation technology, specialized translation, tuition fee and educational time.
\end{abstract}

Keywords - training of professional translators; translation technology; mti; UK universities; Chinese universities

\section{INTRODUCTION}

As we all know, competent language and communication skills are very important for both individuals and businesses to effectively communicate with each other. The study of translation and interpreting gives learners the opportunity to work with language pairs to enjoy excellent job prospects. In today's globalizing world, well-educated and well-qualified translators and interpreters are more likely to excel in the world-wide translation market of billions of dollars.

The academic infrastructure and faculty's competence in UK universities laid the foundation for top-quality training of professional translators. Generally, they aim to train students for MA in Translation and Interpreting Studies (MATIS), which is one of the longest-running and most comprehensive postgraduate degrees in translation and interpreting offered in the UK. MATIS aims to equip students with the knowledge and skills for a career in translation or other cross-cultural professions.

\section{EDUCATIONAL PROGRAMS FOR PROFESSIONAL TRANSLATORS IN THE UK}

\section{A. Educational Programs in the University of Manchester}

Many universities in the UK provide educational programs for students from every corner of the world. However, it is estimated that the University of Manchester (UoM) is the first choice of many students, especially of Chinese students, in pursuing a higher degree in Translation Studies. Firstly, it has a rich heritage of over 180 years and an exciting agenda for the future. It witnessed many major advances of the $20^{\text {th }}$ century including the birth of the computer, the splitting of the atom and the founding principles of modern economics. Major publications from the Centre for Translation and Intercultural Studies (CTIS) include Routledge Encyclopedia of Translation Studies, In Other Words, Translation and Conflict: A Narrative Account, Introducing Corpora in Translation Studies, Audiovisual Translation: Theories, Methods and Issues, Scientific and Technical Translation and The Translator, etc. Secondly, it is Britain's largest single-site university, with a long history of hosting visiting academics and students from China. Thirdly, the University of Manchester has the UK's leading research group in translation, interpreting and intercultural studies, with great breadth of research topics, covering translation and conflict, translation and activism, corpus-based translation studies, multimodality and audiovisual translation, translation and science, history of translation, literary translation, interpreting studies, sociological models of translation/interpreting, translation/interpreting pedagogy, etc. For each specific field, a comprehensive reading list is provided. For example, in the course of Research Methods in Translation and Interpreting Studies I and II, In Other Words: A Coursebook on Translation (2011) by Mona Baker. Discourse and the Translator (1990) and The Translator as Communicator (1997) by Basil Hatim and Ian Mason, The Map: A beginner's guide to doing research in translation studies (2002) by Jenny Williams and Andrew Chesterman are listed as core books for students' reference. In consideration of the increasing number of Chinese students, a specially-designed English-Chinese reading list is also provided as preparation for the MA program.

Sponsored partially by Ministry of Education Youth Project (No. 15YJC740078). 
Academic seminars in Translation Studies are held regularly in CTIS of UoM. Many scholars from all over the world are invited to give lectures to students and visiting academics, to help them keep in touch with the latest development in Translation Studies. International speakers are from University College London, the University of Austria, the University of Edinburgh, Heriot-Watt University, Dublin City University, etc. Additionally, $\mathrm{PhD}$ peer presentations are a good means of academic exchange. For example, in December 2015, PhD peer presentations include: Reflections or Projections? Iraqi Women Writers in Arabic-English Translation and Feminist Translation Approaches, Fragmented Narratives, Twitter and the 3 July 2013 Military Intervention in Egypt, Tracing Competence Development from a ProblemSolving Perspective: A Longitudinal Study among Translation MA Students, Translating Dialect in Literary Texts with Particular Reference to Arabic Regional Dialects, The Mutual Relationship between Political Press Conference Interpreters and Their Institutional Employer in Mainland China: A Corpus-based CDA Study, The Clash of Articulations: Aesthetic Shock, Multivalent Narratives and Islam in the Post9/11 Era, The Translation of Children's and Adolescents' Literature in Iran: A Structurationist Approach, Re-narrating the City: A Genetic Investigation into the Narrative Impact of the Translation Practices of Wikipedia Volunteers, Renarrating the Berbers in Three Tamazight Translations of the Holy Quran: Para-textual and framing strategies, Managing Translation Projects: Collaboration and Quality in Production Networks, Investigating the Multimodal Construal and Reception of Irony in Film Translation: An Experimental Approach, The Positioning of Web-based Media Outlets in the Coverage of the Palestinian-Israeli Conflict: A Bourdieusean Analysis, etc. After each presentation, relevant questions or criticism or suggestions are made to help each presenter to better conduct their creative and inspiring research. UoM also provide masterclasses to introduce students to scholarly research, and offer them valuable opportunities to learn from leading academics and keep in touch with the latest development in the field of Translation Studies.

\section{B. Educational PROGRAMS in University College London}

The Centre for Translation Studies (CenTraS) in University College London (UCL) is also very competent in training professional translators and interpreters. Its research and teaching focus on audiovisual translation, specialized translation, translation technology and interpreting. Like CTIS of the University of Manchester, CenTraS of UCL also offers a wide range of high-quality courses for students' professional development in different areas of Translation Studies. Mcs in Specialized Translation (Scientific, Technical and Medical) is designed to provide first-class training in specialized translation in the scientific, technical, medical areas, etc. The program will equip students with the skills in a variety of registers and styles for professional translation and for further academic research in Translation Studies.

Scientific, technical and medical texts including scientific reports, popular science articles, peer-reviewed articles, healthcare documents, clinical case studies, user guides, and technical specifications, are included in the training modules in various language pairs. Core modules include Language \& Translation, Translation Technology, Medical Translation, Language \& Automation, and Scientific \& Technical Translation. Additionally, Inside the Translation Industry provides students with useful ideas about how to move into the professional career. These seminars will help students to get a better understanding of their future career. Sessions are delivered by translation professionals from different backgrounds, institutions and companies, including past students of the MSc, who talk about their areas of specialization: audiovisual translation, specialized translation, freelancing, transcreation, accessibility, project management, localization, $\mathrm{CVs}$, and much more.

As a matter of fact, to improve translation quality and translation efficiency, professional translators relies on translation software like SDL Trados, which includes translation memory programs and Multiterm management programs. Therefore, in the study of Translation Technology in CenTraS, the leading software Trados Studio 2015 is introduced regarding its translation memories, termbases, workbench, alignment, SDL cloud technologies and editors. Students can also choose to study Transit, Across, MemoQ, depending on the corresponding students' preference and the trainer's educational background. After studying the educational program, students can grasp the essential skills for translators including project management, google translation or machine translation, multiterm edition, software or website localization, etc.

\section{Educational Programs in the University of Leeds}

Similar to the translation training in the UoM and UCL, other universities also provide educational programs for translators and interpreters. For example, the Centre for Translation Studies (CTS) in the University of Leeds (UoL) hosts such Masters programs as MA Applied Translation Studies (MAATS), MA Conference Interpreting and Translation Studies (MACITS) and MA Audiovisual Translation Studies (MAAVTS). It also offers Postgraduate Diplomas in Conference Interpreting (PG Dip CI) and Applied Translation Studies (PG Dip ATS). These professional programs help to facilitate students in developing different skills required by professional interpreters, translators and subtitlers, with a solid foundation in translation theory.

CTS in UoL also conduct research in many aspects of translation studies. The areas of research and knowledge transfer include: literary translation: style, voice, poetry translation; reception and Descriptive Translation Studies; sociology of literary translation; translation and ideology (analysis of critical points and shifts in ideology in translated and interpreted texts using systemic functional grammar and critical discourse analysis); translation quality standards in translation; multilingual, multimodal analysis (working with audiovisual material, such as film, and digital and graphic documents in multilingual contexts); interpreting training and 
other aspects of interpreting studies (conceptualization of pedagogy in interpreter training, corpus-based study of the interpreting process and product, etc.); evaluation of Machine Translation (how to know MT is good or fit for purpose); computer-assisted translation (how to use computers in human translation, e.g. for collaborative translation, terminology research, editing MT output); Computer-Assisted Language Learning (how to use computers to improve reading skills in a foreign language or how to develop the lexicon for a learner); methods for the collection, enrichment and analysis of monolingual and multilingual corpora (how to collect a corpus harvesting large-scale linguistic resources from the web and explore its contents automatically); document classification (how to detect a text is on a given topic or in a given genre); use of eye-tracking in research on translation, subtitling and language learning. Their research aims to find solutions to problems facing practicing professional or non-professional translators, subtitlers and interpreters.

Except for courses and seminars listed in the curriculum, there are also relevant workshops, events, short-term summer school, running throughout the academic year, including research methods, writing guidance, reading skills development, etc. All these education programs in different universities can help students reinforce their language skills and translation skills, train them with new IT technology and computer-aided translation technology, and reward them with an internationally-recognized qualification in translation for their future career in this field.

\section{OTHER RESOURCES FOR THE TRAINING OF PROFESSIONAL TRANSLATORS}

Except for classes, seminars, etc., resources can also be easily accessed in university libraries with all the major databases in almost every discipline. In UoM, the Main Library and Alan Gilbert Learning Commons have large computer clusters and discussion rooms while the John Rylands Library boasts a large collection of rare academic resources. As for UCL, it has more resources as students can benefit not only from its own bibliographical resources but also have access to all other university libraries in the city of London, thanks to the agreements UCL has with the other universities in London.

While in the University of Leeds, there are also many facilities for the education of professional translators. The Electronic Resources and Information Centre (ERIC) provides 42 high-spec PCs, high-speed internet access and an outstanding range of language software, including the specialized computer-assisted translation software such as Trados, Transit, which are the focus of the MA Applied Translation Studies and the subtitling software that is the focus of the MA Audiovisual Translation Studies. The PCs are arranged in groups so that students can easily form a team to work together. Students have easy access to the computers, translation software and all internet resources. They can use the resources to work like any professional translator to acquire essential theoretical knowledge and practical translation skills for their future career. It also has conference suites for interpreter training, which is composed of two conference venues with computers and projectors, and both single and double booths for interpreters. They are well equipped to offer students excellent opportunities to practice their own interpreting skills and improve their interpreting performances. Also available are Michael Sadler Building, the Human Communications Laboratory, which provide support for student's research work and practical training.

\section{POTENTIAL CAREERS}

The MA graduates in the UK pursue a very wide range of careers in professional translation, conference interpreting, liaison interpreting, software localization, language services, publishing, business, project management, subtitling, terminology, proof reading, etc. The best career might be to combine the competences in languages and knowledge in specialized fields. In other words, translations are not only conducted across languages like English, Chinese, French, but also across disciplines including arts, science, technology, etc. Under certain circumstances, translators usually need to collaborate with a big team of professionals and experts in different fields in order to render the original texts into the target texts.

With the development of information technology, translations can be done offline or in the emerging online translation market. When working offline, translators and interpreters might have plenty of opportunities to travel and work with people from all around the world and enjoy a rich and fascinating cultural experience. When working online, they can save the travel time and concentrate on their work, individually or in a group, to provide translation services to any corner of the world.

\section{IMPLICATIONS TO THE TRAINING OF PROFESSIONAL TRANSLATORS IN CHINESE UNIVERSITIES}

\section{A. On Translation Technology}

Translation technology is one of the major foci in the training of professional translators in the UK. However, in China, this important development of Translation Studies is not given enough attention to. As far as we know, in the teaching aims in UoM, UCL, UoL, etc., the mastery of computer-aided translation software like SDL Trados, STAR Transit, LTC Organizer, OmegaT, and Wordfast are prerequisite of the Master's Degree. SDL Trados is originally developed by the German company Trados GmbH and currently available from SDL plc, a provider of customer experience cloud solutions. It is considered the market-leader in providing translation software solutions across the entire translation supply chain, including freelance translators, language service providers, corporate language departments and academic institutions. The application of such software is very important for the high efficiency and high quality in translation practice. Hopefully, the introduction of SDL Trados can be implemented in Chinese Universities to catch up with 
the increasing requirement of translation quality, translation efficiency and translation costs.

\section{B. On Specialized Translation}

According to the definition of Wikipedia, specialized translation is the translation of content which presents a high or very high level of specialization in a specific area of knowledge where previous knowledge of the material on the part of the translator and/or reviewer is a basic and essential requirement.

Technical translation is a type of specialized translation involving the translation of documents produced by technical writers including manuals, user guides, etc., or more specifically, texts related to technological subject areas or texts dealing with the application of scientific and technological information. Technical translation requires a high level of subject knowledge. Translators should master the relevant terminology and writing conventions, according to the specific genre and style.

It is never too much to emphasize the importance of consistent terminology in technical translation. Fortunately, computer-assisted translation with translation memories and multiterm databases can make this task easier.

Considering the fact that specialized translation is very popular in the UK, while not so well studied in China, we need to think about changes in Chinese universities. For example, in the UK, Many graduates from the Master's program work in the field of specialized translation. Their advanced training modules can be borrowed and adapted in the Chinese training programs of professional translators.

\section{On Tuition Fee and Educational Time}

The tuition fees in the UK are quite high, especially for international students. In UoM, the tuition fees beginning from September 2016 for a full-time Mater of Philosophy are $£ 4,121$ per annum for UK/EU students and $£ 15,500$ per annum for international students. In UoL, the annual fee of a Research MA is $£ 4,250$ for UK/EU students and $£ 14,500$ for international students. UCL's tuition fees for 2016 entry are set at $£ 9,000$ per year for UK and EU students, while $£ 16,130$ for most Arts, Humanities and Social Science-based programs. The difference of more than $£ 10,000$ in UoM and UoL makes it quite unfair for internationals students (In UCL, the difference between UK/EU students and international students are smaller, but international students need to pay even higher tuition fee). In light of the expensive tuition fee, still many international students, most of whom from China are willing to receive education in the UK. Many reasons, including highquality education, world-recognized certificate, latest development in the field, lead to their preference of studying in the UK. Another factor we cannot neglect is the short length of the educational program. In China, an Academic Master's degree takes up to three years and a Professional Master degree two years, while in the UK, it takes only one year's intensive study and research. If the time span of the Master's program in Chinese universities is shortened to one and a half years, or even one year, it could be expected that more and more Chinese students would no longer go abroad to spend so much money in the Master's program. It's not only a problem in the training of professional translators, but also in other educational programs including arts, science and technology, etc.

\section{REFERENCES}

[1] Austermühl, Frank. Electronic Tools for Translators. Beijing: Foreign Language Teaching and Research Press, 2006.

[2] Bowker, Lynne. Computer-Aided Translation Technology: A Practical Introduction, Ottawa : University of Ottawa Press, 2002.

[3] Byrne, Jody. Scientific and Technical Translation Explained: A Nuts and Bolts Guide for Beginners, St. Jerome Publishing, 2012.

[4] http://documents.manchester.ac.uk/display.aspx?DocID=16555/

[5] http://www.alc.manchester.ac.uk/subjects/tis/

[6] http://www.leeds.ac.uk/arts/info/125053/centre_for_translation_studies/

[7] http://www.nationalnetworkforinterpreting.ac.uk/

[8] http://www.sdl.com/cxc/language/

[9] http://www.ucl.ac.uk/centras/

[10] https://en.wikipedia.org/wiki/

[11] Lombardino, Rafa. Tools and Technology in Translation: The Profile of Beginning Language Professionals in the Digital Age. CreateSpace Independent Publishing, 2014.

[12] Olohan, Maeve. "Gate-keeping and localizing in scientific translation publishing: The case of Richard Taylor and Scientific Memoirs". British Journal for the History of Science, 2014: 47(3), 433-450.

[13] Olohan, Maeve. Scientific and Technical Translation. (Routledge Translation Guides). London and New York: Routledge, 2015.

[14] Olohan, Maeve, \& Myriam Salama-Carr. "Translating science". The Translator, 2011: 17(2).

[15] Zhang Xiaojun, "Teaching of translation technology in UK universities and its implication", Foreign Language Research, 2010 (6). 